\title{
O atual cenário da produção de energia eólica no Brasil: Uma revisão de literatura
}

\author{
The current scenario of wind energy production in Brazil: A literature review \\ El escenario actual de la producción de energía eólica en Brasil: Una revisión de la literatura
}

Recebido: 18/01/2021 | Revisado: 19/01/2021 | Aceito: 25/01/2021 | Publicado: 31/01/2021

\author{
Keila Regina Alves Sampaio \\ ORCID: https://orcid.org/0000-0002-7741-0329 \\ Instituto de Ensino Superior Blauro Cardoso de Mattos, Brasil \\ E-mail: ksampaio1993@gmail.com \\ Valmir Batista \\ ORCID: https://orcid.org/0000-0002-1468-5966 \\ Instituto de Ensino Superior Blauro Cardoso de Mattos, Brasil \\ E-mail: batista-engenharia2013@hotmail.com
}

\begin{abstract}
Resumo
O recurso eólico na produção de energia elétrica vem ganhando cada vez mais espaço no Brasil e no mundo, pois além de ser uma energia limpa, ela possui inúmeros benefícios que são de interesse global e econômico. Deste modo o objetivo deste estudo é mostrar dados recentes da evolução da capacidade de energia eólica no Brasil; os impactos da COVID-19 na indústria eólica no setor nacional e demonstrar as questões relacionadas ao atual cenário do setor eólico. Metodologia, é um estudo bibliográfico, de cunho qualitativa. Resultados obtidos: nos últimos anos, a energia eólica cresceu de forma significativa e mesmo com a atual crise econômica mundial, dados mostram que o setor eólico está se expandindo no país e que a geração espera um futuro promissor, pois o Brasil possui um grande potencial em recursos eólicos que ainda precisam ser explorados.
\end{abstract}

Palavras-chave: Energia eólica; Capacidade energética; Setor eólico.

\begin{abstract}
The wind source in the production of electric energy has been gaining more and more space in Brazil and in the world, because besides being clean energy, it has numerous benefits that are of global and economic interest. Thus, the objective of this study is to show recent data on the evolution of wind energy capacity in Brazil; the COVID-19 impacts on the wind industry in the national sector and demonstrate the issues related to the current scenario of the wind sector. Methodology, is a bibliographic study, of qualitative nature. Results obtained: in recent years, wind energy has grown significantly and even with the current global economic crisis, data show that the wind sector is expanding in the country and that the generation expects a promising future, as Brazil has great potential in wind resources that still need to be explored.
\end{abstract}

Keywords: Wind energy; Energy capacity; Wind sector.

\section{Resumen}

El recurso eólico en la producción de energía eléctrica ha ido ganando cada vez más espacio en Brasil y en el mundo, porque además de ser energía limpia, tiene numerosos beneficios que son de interés global y económico. Así, el objetivo de este estudio es mostrar datos recientes sobre la evolución de la capacidad eólica en Brasil; El Covid - 19 impacta en la industria eólica en el sector nacional y demuestra los problemas relacionados con el escenario actual del sector eólico. Metodología, es un estudio bibliográfico, de carácter cualitativo. Resultados obtenidos: en los últimos años, la energía eólica ha crecido significativamente e incluso con la actual crisis económica global, los datos muestran que el sector eólico se está expandiendo en el país y que la generación espera un futuro prometedor, ya que Brasil tiene un gran potencial. en recursos eólicos que aún necesitan ser explorados.

Palabras clave: Energía eólica; Capacidad energética; Sector eólico.

\section{Introdução}

Nos últimos anos, a produção de energia elétrica por meio de fontes renováveis vem sendo o centro de muitos debates e pesquisas, e tudo isso deve-se aos problemas ambientais consequentes da emissão de gases do efeito estufa, através da liquidação de combustíveis fósseis como um meio à geração energética. Sendo Assim, a energia eólica, que é uma das fontes de energia sustentável, vem sendo cotada como uma das soluções de maior potencial no mundo. No Brasil, esse tipo de geração é bastante viável, pois segundo a Associação Brasileira de Energia Eólica (ABEEólica; 2020), o potencial eólico no país é de 744.95MW, onde se destaca as regiões do norte e nordeste, e isso porque o Brasil tem o dobro de volume de ventos 
em relação à média mundial e menor oscilação da velocidade, o que garante à geração de eletricidade por meio de fonte eólica.

Segundo Santos (2018, p.9), “A importância que a eletricidade exerce desde a saúde, economia, explorações espaciais até a agricultura, lazer e esportes é indiscutível". Ou seja, ela está presente em praticamente tudo o que realizamos em nosso cotidiano, sendo utilizada também como fonte de calor, telecomunicações, luz, força, e entre outros.

Para França (2017, p.14), “Um dos grandes tormentos do mundo de hoje é a questão relativa à energia: o aproveitamento desta ainda não atingiu um nível satisfatório, visto que a imensa maioria da energia utilizada no planeta é de origem não renovável, seja de fonte mineral ou atômica". À vista disso, surgiu o interesse em explorar mais sobre o assunto, como também obter mais informações que possam contribuir à sociedade dentro do contexto do futuro da produção de energia eólica para o meio ambiente no Brasil.

Assim, o objetivo geral é mostrar estudos sobre a evolução da capacidade e o futuro da produção de energia eólica no Brasil.

Objetivos específicos: apresentar dados recentes da evolução da capacidade de energia eólica no Brasil; os impactos da Covid - 19 na indústria eólica no setor nacional e demonstrar as questões relacionadas ao atual cenário do setor eólico.

\section{Metodologia}

O estudo apresentado é de natureza qualitativa e trata-se de uma revisão de literatura com bases em dados eletrônicos dos livros, artigos, e revistas já publicados nas plataformas de pesquisas Google acadêmico e Scielo, utilizando as palavras chaves (energia eólica. Capacidade energética. Setor eólico) no período de 2017 a 2020. Assim como também se utilizou os dados recentes que foram divulgados nos sites oficiais da ABEEólica e ANEEL. Além disso, a presente revisão de literatura foi elaborada obedecendo as seguintes etapas: Definição do tema, estabelecimento dos padrões de elegibilidade, avaliação das publicações nas bases de sites e plataformas de pesquisas, análises das informações relevantes ao estudo e exposição dos resultados (Pereira, Shitsuka, Parreira, \& Shitsuka, 2018). Como critérios de inclusão no estudo apresentado, foram adotados os artigos que mais se adequavam aos objetivos destacados neste estudo.

Três quadros foram elaborados para mostrar os dados atuais da produção de energia eólica no Brasil. Sendo assim, neles são apresentadas as quantidades de parques eólicos construídos, em construção e os que ainda serão construídos, bem como a potência outorgada, potência fiscalizada e seu percentual de potência outorgada.

\section{Breve Histórico da Energia Eólica no Brasil}

Na década de 90 surgiram os primeiros projetos de energia eólica no brasil, a fonte de energia sustentável ganhou espaço por ser viável à substituição da geração de energia hidrelétrica em algumas regiões, como no norte e nordeste, onde várias comunidades isoladas não eram atendidas pelo fornecimento de energia convencional.

De acordo com a ABEEólica (2020), o nascimento da geração de energia eólica no Brasil se deu com o primeiro aerogerador instalado, iniciando sua operação em 1992, no arquipélago de Fenando de Noronha (PE).

No entanto, Cenários Eólica (2020) afirma que o país sempre priorizava a geração de energia elétrica por meio das hidrelétricas, pois a construção era de baixo custo e acionamento mais flexível, tornando assim uma opção mais vantajosa. Porém, essa perspectiva mudou durante a crise energética de 2001, quando o país se encontrava vulnerável dependendo apenas de uma fonte energética. $\mathrm{O}$ autor diz ainda que, por conta disto, o país somava pressões internacionais para implementar como alternativa, novas fontes de energia elétrica para diminuir os impactos ambientais e o efeito estufa (Protocolo de Quioto).

Por conta disto, segundo Fernando (2019) o governo brasileiro decidiu criar um programa chamado PROEÓLICA cujo objetivo era o incentivo da contratação de mais empreendimento para a geração de energia eólica. No entanto não obteve resultados satisfatórios e logo foi substituído pelo PROINFA, um programa que além de incentivar o desenvolvimento das 
fontes renováveis, também deu espaço à indústria de turbinas eólicas e de componentes no Brasil.

Como aponta a última edição do Plano Decenal de Expansão de Energia (PDE 2026), citado por Castro (2018), as últimas pesquisas realizadas pela Empresa de Pesquisa Energética (EPE) sobre a expansão do setor elétrico, indicam que, até 2026, a taxa de participação da matriz de direção eólica será de 16,14. \% (28.470 MW). Portanto, em termos de potência instalada, as fontes eólicas devem ultrapassar as fontes de energia térmica em 2026, perdendo apenas para a energia hidrelétrica. A política energética do Brasil tem desempenhado um papel importante na promoção da energia eólica.

\begin{abstract}
"Com os vários desafios e com os grandes investimentos em pesquisa e desenvolvimento pode-se afirmar que o aproveitamento da energia eólica para geração de eletricidade ainda tem um longo caminho a percorrer, principalmente em países como o Brasil onde os impactos ambientais, sociais e econômicos ainda não são conhecidos com clareza para cada região com potencial favorável deste recurso energético.” (Pinto, Martins e Pereira, 2017, p. 5)
\end{abstract}

Segundo Miranda et al. (2016), citado por Pinto, Martins e Pereira (2017), "Um dos argumentos básicos contrários está relacionado com a inconstância temporal não controlável e com previsibilidade limitada do recurso eólico e que pode afetar a qualidade da energia distribuída no sistema elétrico". O autor ainda diz que, a força do vento é diretamente afetada pela posição e força dos sistemas de alta e baixa pressão. As mudanças interanuais dos sistemas de alta e baixa pressão e as mudanças interdecadais relacionadas às mudanças climáticas estão presentes. No que se refere à segurança energética do sistema elétrico brasileiro, esses fatores têm trazido obstáculos negativos ao aumento da participação dos recursos eólicos.

\title{
4. Evolução da Capacidade Instalada no Brasil
}

Segundo dados da ABEEólica (2020), a capacidade de instalação de energia eólica no brasil se desenvolveu se ao longo dos anos de forma efetiva a partir do leilão de comercialização de energia ocorrido em 2009 pela LER (Leilão de Energia de Reserva).

O Gráfico 1 representa a evolução da capacidade instalada ao longo dos anos, que se deu pelo crescimento da exploração dos recursos eólicos nas regiões mais privilegiadas com o potencial dos ventos, o que justifica por parte, a expansão gradativa do setor de energia eólica no Brasil.

Gráfico 1. Evolução da capacidade instalada.

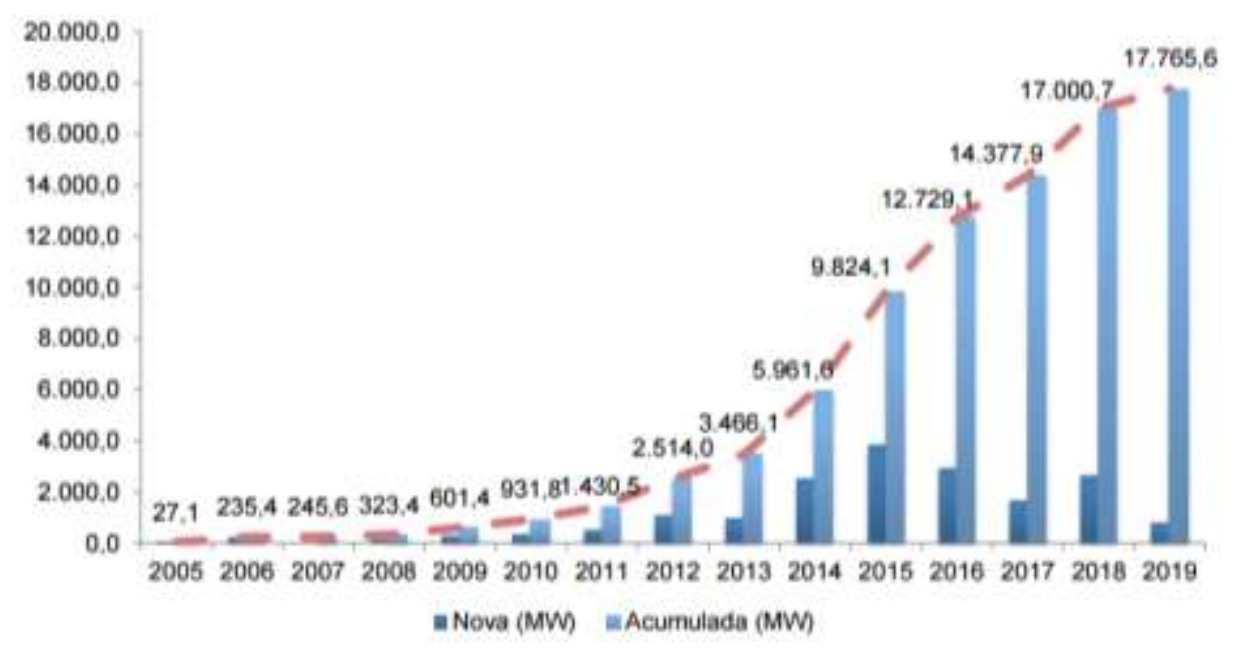

Fonte: abeeolica.org.br.

De acordo com Castro e Oliveira (2018, p. 2), essa evolução está relacionada à qualidade do recurso eólico nas 
regiões nordeste e sudeste e também ao elevado fator de capacidade das fontes eólicas já registradas no país, pois segundo dados levantados entre junho de 2017 e maio de 2018, o fator da capacidade nacional subiu em torno de $41,8 \%$ enquanto a mundial apenas $25 \%$.

$\mathrm{Na}$ Imagem 1 a matriz elétrica brasileira destaca-se entre as regiões do Nordeste, sudeste e partes do sul, onde fica o maior potencial de recursos eólicos do país. No Mapa estes pontos representam os parques eólicos que estão em fase de operação, em construção e também os que a construção ainda não está iniciada. No total são 1026 parques eólicos com 16614902.86 de potência fiscalizada (kW) e 29381338.86 de potência outorgada (kW).

Imagem 1. Matriz elétrica brasileira. Fonte eólica.

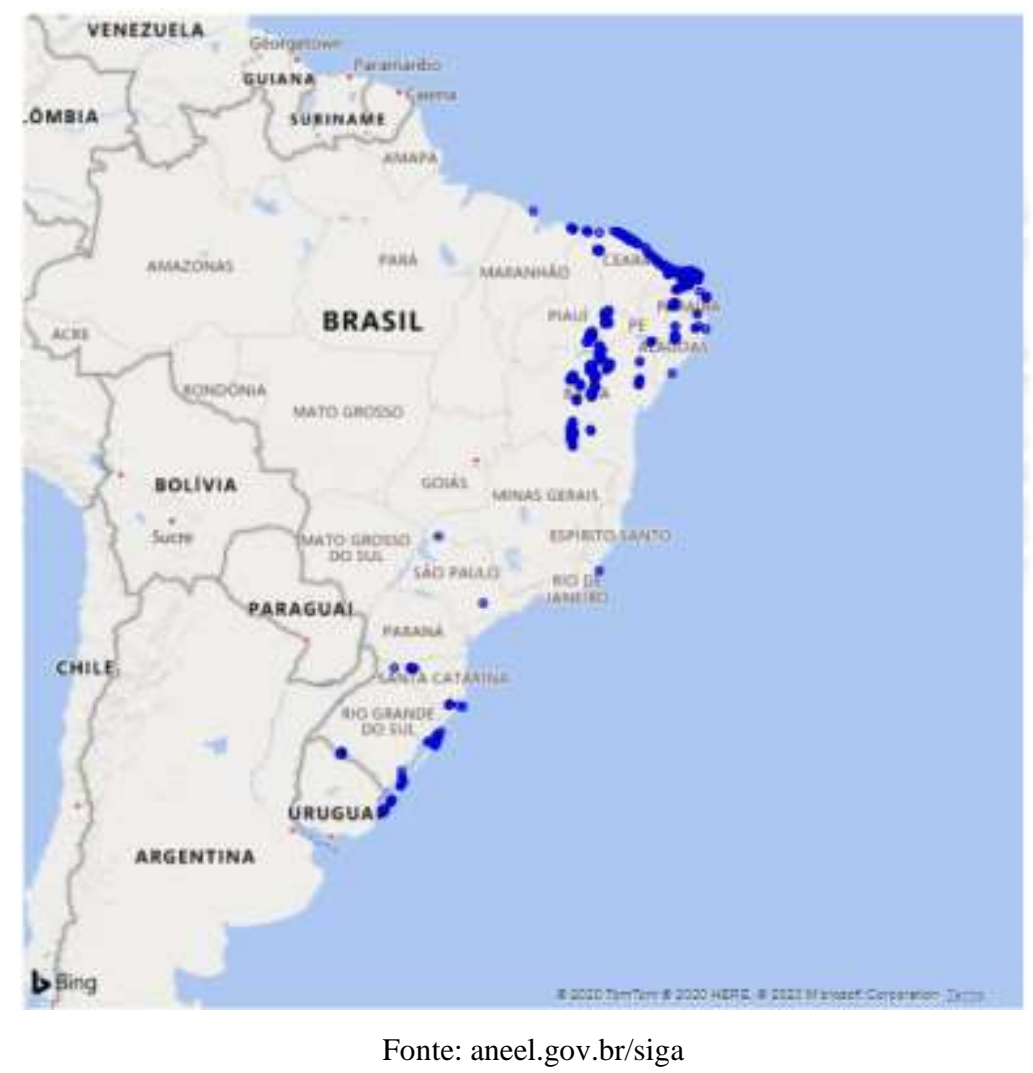

Dados recentes do boletim de informações da ABEEólica afirmam que em 2019, houve um crescimento de $34 \%$ na capacidade média mundial e no Brasil 42,7\%. A cada ano que passa, mais parques eólicos entram em fase de operação, no ano de 2020, o país ficou entre as primeiras posições no Ranking Mundial do Global Wind Energy Council (GWEC), chegando à $7^{\mathrm{a}}$ posição. Estima-se que até o ano de 2024, a capacidade média nacional terá cerca de 24,2 GW.

\subsection{Impactos da COVID - 19 na indústria eólica no setor nacional}

Segundo informações do site oficial da Associação, Grupo CanalEnergia (2020), em entrevista, a presidente executiva da associação Brasileira de energia eólica, Élbia Gannoum, afirmou que a associação ainda está avaliando os impactos causados pelo covid-19 no setor eólico. No entanto, foi criado um comitê de crise e um grupo de trabalho em apoio aos trabalhadores. A mesma afirma ainda que não houve grandes prejuízos nos parques em construção como também na cadeia de suprimentos eólicos. Ainda assim, acredita-se que, a américa latina sofrerá alguns prejuízos com relação à cadeia de suprimentos, na demanda energética e nos projetos de desenvolvimento em curto prazo, como também sofrerá a médio prazo quedas na produção e entre outros problemas relacionados. 
"Sem dúvida, a retomada econômica, pós-pandemia, será de forma sustentável. Não é uma moda", avalia a presidente da Associação Brasileira de Energia Eólica (Abeeólica), Elbia Gannoum. Na avaliação dela, esse movimento não tem volta, até porque as empresas precisam cumprir metas estabelecidas de redução de emissões. Nesse cenário, a energia eólica tem muito a contribuir pelas características. É limpa, o preço da geração é competitivo e há um enorme potencial a ser explorado Brasil afora. "O futuro é renovável, competitivo e sem subsídio.” (Estadão, 2020).

De acordo com a matéria publicada na Imprensa Brasil Windpower (2020), executivos das principais empresas do setor eólico estão preocupados com o aumento dos preços dos componentes importados e com o abastecimento, pois os mesmos temem por um grande prejuízo ao crescimento das eólicas no país, já que o mercado do setor eólico é movimentado conforme a flutuação cambial.

Segundo a matéria, João Paulo Silva, Diretor superintendente da WEG Energia, afirma que:

"Estamos diante de grandes desafios com a cadeia de produção. Nossa grande preocupação é com o abastecimento dos materiais e o custo deles. Estamos vendo um escalonamento muito sério no preço das commodities, como cobre e aço, com aumento bem maior das matérias importadas. Isso preocupa todos os fabricantes, porque isso afeta nossa capacidade operacional de gerar lucros. Esperamos que seja uma condição momentânea e que o abastecimento volte ao normal nos próximos meses.” (Imprensa Brasil Windpower, 2020).

\section{Análises dos Resultados}

\subsection{Questões relacionadas ao atual cenário do setor eólico no Brasil}

Entre os principais resultados analisados neste estudo estão o fato de que a fonte energia eólica é a segunda maior matriz energética do Brasil; nos últimos anos, o setor eólico brasileiro cresceu a níveis bastante significativos, mais de 600 parques eólicos já se encontram em fase de operação; o consumo da energia eólica no Brasil está crescendo consideravelmente nas regiões do nordeste e sudeste.

Embora o país esteja sofrendo problemas econômicos por conta da crise causada pelo surto do Covid-19, a estimativa é de que, segundo a ABEEólica (2020), o setor continue se desenvolvendo com a retomada dos leilões de estrutura que estão previstos para acontecer no segundo semestre de 2021, para que se possa crescer a demanda e continuar a expandir o setor.

A Tabela 1 apresenta os dados do sistema de informações de geração da ANEEL - SIGA, que informam a capacidade energética atual nos estados brasileiros nas fases de operação. 
Tabela 1. Capacidade energética no Brasil com fonte eólica em fase de operação.

\begin{tabular}{|c|c|c|c|c|}
\hline $\mathbf{U F}$ & $\begin{array}{c}\text { Potência } \\
\text { Outorgada (kw) }\end{array}$ & $\begin{array}{c}\text { Potência } \\
\text { Fiscalizada (kw) }\end{array}$ & Quantidade & $\begin{array}{c}\% \text { (Pot. } \\
\text { Outorgada) }\end{array}$ \\
\hline $\mathbf{B A}$ & 4437375.64 & 4415115.64 & 178 & $100 \%$ \\
\hline $\mathbf{C E}$ & 2188840 & 2177964 & 86 & $100 \%$ \\
\hline MA & 426022.5 & 426022.5 & 16 & $100 \%$ \\
\hline MG & 156 & 156 & 1 & $100 \%$ \\
\hline PE & 800365 & 783985 & 35 & $100 \%$ \\
\hline PB & 157200 & 157200 & 15 & $100 \%$ \\
\hline PI & 1764100 & 1745200 & 64 & $100 \%$ \\
\hline PR & 2500 & 2500 & 1 & $100 \%$ \\
\hline RJ & 28050 & 28050 & 1 & $100 \%$ \\
\hline $\mathbf{R N}$ & 4672366 & 4672366 & 169 & $100 \%$ \\
\hline $\mathbf{R S}$ & 1835891.98 & 1832091.98 & 81 & $100 \%$ \\
\hline SC & 245499.5 & 245499.5 & 16 & $100 \%$ \\
\hline SE & 34500 & 34500 & 1 & $100 \%$ \\
\hline SP & 2.24 & 2.24 & 1 & $100 \%$ \\
\hline Total & 16592868.86 & 16520652.86 & 665 & $100 \%$ \\
\hline
\end{tabular}

A Tabela 2 apresenta os dados do sistema de informações de geração da ANEEL - SIGA, que informam a quantidade de parques eólicos em construção no país, com a maioria deles na região nordeste e somente um na região sul.

Tabela 2. Capacidade energética no Brasil com fonte eólica em fase de construção.

\begin{tabular}{ccccc}
\hline UF & $\begin{array}{c}\text { Potência } \\
\text { Outorgada (kw) }\end{array}$ & $\begin{array}{c}\text { Potência } \\
\text { Fiscalizada (kw) }\end{array}$ & Quantidade & $\begin{array}{c}\text { \% (Pot. } \\
\text { Outorgada) }\end{array}$ \\
\hline BA & 1314720 & 0 & 53 & $100 \%$ \\
\hline CE & 205800 & 0 & 8 & $100 \%$ \\
\hline PB & 471240 & 0 & 24 & $100 \%$ \\
\hline PI & 798450 & 0 & 27 & $100 \%$ \\
\hline RN & 1121400 & 0 & 3 & $100 \%$ \\
\hline RS & 52500 & 0 & $\mathbf{1 3 0}$ & $\mathbf{1 0 0 \%}$ \\
\hline Total & $\mathbf{3 9 6 4 1 1 0}$ & $\mathbf{0}$ & & $100 \%$ \\
\hline
\end{tabular}


A Tabela 3 apresenta os dados do sistema de informações de geração da ANEEL - SIGA, que informam a quantidade de parques eólicos com construção não iniciada, onde todos se encontram somente na região nordeste.

Tabela 3. Capacidade energética no Brasil com fonte eólica em fase de construção não iniciada.

\begin{tabular}{ccccc}
\hline UF & $\begin{array}{c}\text { Potência } \\
\text { Outorgada }(\mathbf{k w})\end{array}$ & $\begin{array}{c}\text { Potência } \\
\text { Fiscalizada }(\mathbf{k w})\end{array}$ & Quantidade & $\begin{array}{c}\text { \% (Pot. } \\
\text { Outorgada) }\end{array}$ \\
\hline BA & 2843210 & 0 & 80 & $100 \%$ \\
\hline CE & 238200 & 0 & 9 & $100 \%$ \\
\hline PB & 329175 & 0 & 9 & $100 \%$ \\
\hline PE & 275400 & 0 & 9 & $100 \%$ \\
\hline PB & 329175 & 0 & 28 & $100 \%$ \\
\hline PI & 1251800 & 0 & 85 & $100 \%$ \\
\hline RN & 3271375 & 0 & $\mathbf{2 1 8}$ & $100 \%$ \\
\hline Total & $\mathbf{8 2 0 9 1 6 0}$ & $\mathbf{0}$ & $\mathbf{1 0 0 \%}$
\end{tabular}

Fonte: aneel.gov.br/siga.

\section{Conclusão}

Diante das observações, e pesquisas realizadas, foi possível constatar que apesar de ser uma energia limpa e sustentável, a energia eólica é um recurso ainda pouco usado no Brasil.

O estudo mostrou também que a matriz energética está em constante evolução, mas que de acordo com dados destacados neste artigo, o seu potencial ainda não está sendo aproveitado em sua total expansão, pois há muitos parques eólicos que ainda estão sendo construídos e outros que a construção ainda não foi iniciada.

Verifica-se ainda que apesar da boa capacidade de gerar energia por meio de fontes eólicas no Brasil, o setor eólico sofre por consequências do atual cenário econômico mundial, pois os investidores estão mais preocupados em se preservar do que de fato avançar em novos empreendimentos.

Portanto, para trabalhos futuros, os autores pretendem avançar com novas pesquisas na área do setor eólico, possibilitando o acesso aos dados atualizados de informações sobre o real impacto na produção de energia eólica no Brasil póspandemia. Além disso, estudos futuros abordando projetos para o avanço na geração dessa energia renovável, poderiam contribuir de forma sistemática para a conscientização dos leitores sobre novas ideias voltadas ao aproveitamento do potencial eólico no país.

\section{Referências}

ABEEólica dialoga para avaliar impactos da Covid-19. (2020). Canal Energia. https://www.canalenergia.com.br/noticias/53133107/abeeolica-dialoga-paraavaliar-impactos-da-covid-19

Associação Brasileira de Energia Eólica (ABEEólica). (2019). Boletim anual de geração eólica 2019. http://abeeolica.org.br/wpcontent/uploads/2020/07/EN_Boletim-Anual-de-Gera\%C3\%A7\%C3\%A3o-2019-1.pdf

Castro, N., \& Oliveira, C. (2018). A energia eólica no Brasil e no mundo: desafios e perspectivas, 1-4. https://www.canalenergia.com.br/artigos/53072227/aenergia-eolica-no-brasil-desafios-eperspectivas.

da Silva, S. S. F., Alves, A. C., \& Ramalho, Â. M. C. (2020). Energia Eólica E Complementaridade Energética: Estratégia E Desafio Para O Desenvolvimento Sustentável Na Região Nordeste Do Brasil. Qualitas Revista Eletrônica, 19(3), 53-72. 
Research, Society and Development, v. 10, n. 1, e57710112107, 2021

(CC BY 4.0) | ISSN 2525-3409 | DOI: http://dx.doi.org/10.33448/rsd-v10i1.12107

Fernandes, G. D. S. (2019). Modelo de dinâmica de sistemas para avaliar a capacidade instalada de energia eólica no Brasil.

França, M. (2017). O Histórico da Gestão da Energia Elétrica no Brasil (Bachelor's thesis).

Miranda, R., Soria, R., Schaeffer, R., Szklo, A., \& Saporta, L. (2017). Contributions to the analysis of "Integrating large scale wind power into the electricity grid in the Northeast of Brazil" [Energy 100 (2016) 401-415]. Energy, 118, 1198-1209.

Pereira, A. S., Shitsuka, D. M., Parreira, F. J., \& Shitsuka, R. (2018). Metodologia da pesquisa científica. [e-book]. Santa Maria. Ed. UAB/NTE/UFSM. https://repositorio. ufsm. br/bitstream/handle/1/15824/Lic_Computacao_Metodologia-Pesquisa-Cientifica. pdf.

Pereira, R. (2020). 'No pós-pandemia, retomada econômica terá de ser sustentável', diz presidente da Abeeólica. Estadão. https://economia.estadao.com.br/noticias/geral,no-pos-pandemia-retomada-economica-tera-de-ser-sustentavel-diz-presidente-da-abeeolica,70003384416

Os impactos da pandemia na cadeia produtiva do setor eólico preocupam principais players do setor. (2020). Brazil Windpower. https://www.brazilwindpower.com.br/pt/IMPRENSA/RELEASES/impactos-da-pandemia-na-cadeia-prudutiva-do-setor-eolico-preocupam-principaisplayersdosetor.html

Pinto, L. I. C., Martins, F. R., \& Pereira, E. B. (2017). O mercado brasileiro da energia eólica, impactos sociais e ambientais. Revista Ambiente \& Água, 12(6), $1082-1100$

Plano Decenal de Expansão de Energia 2026. (2020). EPE. https://www.epe.gov.br/pt/publicacoes-dados-abertos/publicacoes/Plano-Decenal-de-Expansao-deEnergia-2026

Informativo da ENGIE Brasil. 2018. Revista Boas Novas, 64 (8). http://abeeolica.org.br/wp-content/uploads/2018/06/REVISTA_BOAS_NOVAS_64_V8.pdf

Ribeiro, P. F. (2020). Desenvolvimento da indústria eólica no Brasil nos últimos 20 anos.

Santos, C. S. (2018). Instalações elétricas: novas concepções. 